\title{
doispontos:
}

\section{Agostinho e o tempo da alma.}

\author{
Augustine and the time of the soul.
}

\author{
Cristiane Negreiros Abbud Ayoub ${ }^{1}$ \\ Universidade Federal do ABC - UFABC \\ cristianenaa@gmail.com
}

\begin{abstract}
Resumo: Um marco sobre a questão do tempo na História da Filosofia, o livro XI das Confissões de Agostinho de Hipona (354-430) ainda hoje recebe interpretações. O presente artigo menciona pontos que já apresentei noutro texto sobre o tempo como espelho da alma, no entanto ele recebe o acréscimo de dois pontos que mudam a ênfase de minha interpretação prévia: (1) a citação a Josué e (2) a escolha de Deus creator ominum para exemplificar a relação, via tempo, entre ser humano, Deus e o mundo. Mediante a análise textual do livro XI, a seguinte conclusão será encaminhada: embora Agostinho não recuse a existência do tempo como uma realidade independente das vivências humanas, ele privilegia outro aspecto do tempo, medular nas Confissões, a saber, a relação humana com o tempo em correspondência com a intenção da vontade pela qual a vida humana é governada. Em Agostinho, o tempo da vida se compromete com a ética, e reflete o modo como a vontade habita a vida. Tempo e alma, nas Confissões, são interdependentes a ponto de a experiência humana do tempo ser um espelhamento da vontade.
\end{abstract}

Palavras-chave: Agostinho, tempo, eternidade, vontade, jubilus, canto.

\begin{abstract}
A landmark on the question of time in the History of Philosophy, the book XI of the Confessions of Augustine of Hippo (354-430) receives interpretations still today. This article mentions some points I have presented in another text about time as a mirror of the soul, but it brings two new points which shifts the emphasys of my previous interpretation: (1) the analysis of Augustine's commentary to Joshua and (2) the choice of Deus creator omnium to exemplify the relationship between human beings, God and the world. Through textual analysis of Book XI, the following conclusion will be drawn: although Augustine does not reject the existence of time as an independent reality of human experiences, he privileges another aspect of time, which is central to the Confessions, namely, the human relationship with time in correspondence with the intention of the will by which human life is governed. According to Augustine, the time of life is committed to ethics and reflects the way the will inhabits life. In the Confessions, time and soul interdependent to the point that the human experience of time mirrors his will.

Keywords: Augustine, time, eternity, will, jubilus, chanting.
\end{abstract}

\footnotetext{
${ }^{1}$ Presidente do CEPAME (Centro de Estudos de Filosofia Patrística e Medieval de São Paulo - http://cepame.fflch.usp. br/) e vice-coordenatora do Grupo de Trabalho História da Filosofia Medieval e a Recepção da Filosofia Antiga (https:// gtfilosofiamedieval.wordpress.com/).
} 


\section{Sobre a pertinência de se considerar a relação entre tempo e vontade no livro XI das Confissões.}

No prólogo do livro XI das Confissões, Agostinho anuncia sinteticamente a temática dessa unidade, relacionando eternidade, tempo e vontade. Analisaremos esse prólogo com o intuito de comprovar a pertinência e a relevância da relação entre tempo e vontade no referido livro.

O autor inicia assim: "Porventura, senhor, sendo tua a eternidade, ignoras o que te digo, ou vês com o tempo o que se passa no tempo?” (AGOSTINHO, Confissões, XI, 1, 1; 2009, p. 26). ${ }^{2}$ O primeiro aspecto a ser destacado desta pergunta é que ela apresenta a temática do livro XI: a eternidade divina em sua relação com o escritor das Confissóes (imerso na temporalidade). Essa pergunta expressa a desproporcionalidade entre quem pergunta e escuta (Agostinho, porta-voz dos humanos) e seu destinatário (Deus, seu superior e detentor da eternidade). Em um polo dessa comunicação está Agostinho (porta-voz de seus leitores), que faz a pergunta e abre-se à busca e à escuta da resposta. No outro polo desse diálogo, coloca-se o destinatário único, superior e detentor da eternidade. A incompatibilidade entre esses dois polos não impede sua comunicação, embora requeira um esclarecimento sobre como a eternidade se faz presente no tempo.

Com efeito, traduzimos o pronome interrogativo latino "numquid" por "porventura", na falta de uma palavra ou de uma expressão cujo significado lhe equivalesse em língua portuguesa. Em latim, "numquid" introduz perguntas que exigem respostas necessariamente negativas. Assim, a pergunta "Porventura, senhor, sendo tua a eternidade, ignoras o que te digo, ou vês com o tempo o que se passa no tempo?" é a afirmação de que Deus está presente no tempo, pois (1) ele não ignora o que lhe é dito, embora isto apareça na temporalidade, (2) tampouco conhece "com o tempo o que se passa no tempo". O modo da presença e do conhecimento divinos no tempo é distinto daquele característico dos seres temporais, e isso é marcado por Agostinho através de duas qualidades exclusivas de Deus: a eternidade e a superioridade em relação às criaturas. Se Deus não ignora a narrativa humana temporal e prescinde de que esta seja manifestada no tempo, então ele a conhece ao modo da eternidade. Nesse sentido, Deus, mesmo tendo a eternidade e sendo criador, tem acesso ao tempo, pois não ignora o que ocorre no tempo. Portanto, a presença da eternidade no tempo se dá como onisciência.

A onisciência refere-se à simultaneidade do conhecimento divino, à imutabilidade divina e à presença divina no tempo. Simultaneidade, pois o acesso divino às coisas que se mostram no decorrer do tempo independe da aparição fragmentada delas no tempo, o que significa que Deus as conhece simultaneamente, sem a dissipação e a variação entre aparição e ocultamento característicos da temporalidade. Imutabilidade, uma vez que, se Deus conhece tudo sempre, e ele jamais passa a conhecer algo que ele antes não conhecia, então o conhecimento divino é eterno e perfeito, porque não muda, muito embora Deus conheça coisas mutáveis. Presença, uma vez que Deus tem acesso à totalidade das coisas que já foram ou serão manifestadas no tempo. Mas essa presença divina se manifesta no interior do tempo para os seres humanos? Ou, em outros temos, como ela é vivenciada?

A resposta para essa questão encontra-se no texto imediatamente seguinte àquele supracitado. Lemos:

"Então por que disponho para ti narrações de tantas coisas? Não é, claro, para que venhas a sabê-las por mim, mas excito meu afeto em tua direção e também os afetos daqueles que as leem, para que digamos todos: 'Tu és grande, senhor, e infinitamente louvável' (Salmos 48 (47), 1; 96 (95), 4; 145 (144), 3)." (AGOSTINHO, Confissões, XI, $1,1 ; 2009$, p. 27; grifos nossos) $)^{3}$

\footnotetext{
2 "numquid, domine, cum tua sit aeternitas, ignoras quae tibi dico, aut ad tempus vides quod fit in tempore?"

3 "cur ergo tibi tot rerum narrationes digero? non utique ut per me noveris ea, sed affectum meum excito in te, et eorum qui haec legunt, ut dicamus omnes, 'magnus dominus et laudabilis valde."
} 
A questão que se apresenta é: se Deus não passa a conhecer nada além daquilo que ele já conhece através da narrativa humana (e esta é temporal, pois transcorre no tempo), esta é excessiva e desnecessária para Deus; então qual é a razão desta narrativa que nada informa a seu ouvinte? ("Então por que disponho para ti narrações de tantas coisas?") A relevância de narrar temporalmente algo para Deus consiste no exercício da vontade daquele que narra. A elaboração da narrativa, no interior do tempo, "excita" os afetos humanos. Ex-cita, ou seja, chama para fora da temporalidade em direção à eternidade. Tal excitação ocorre não apenas no narrador, mas inclui aqueles que o leem. A razão disso é que todos os seres humanos compartilham um desejo comum de serem felizes no deleite do louvor a Deus. ${ }^{4}$

No tocante ao exercício narrativo, este é especialmente significativo no contexto de uma obra que apresenta a narrativa biográfica de Agostinho nos nove livros iniciais, e, portanto, a pergunta de Agostinho sobre a pertinência do exercício narrativo deve ser entendida também como a pergunta pelo sentido de tal obra. No entanto, não avançaremos nesse estudo porque o enfoque do presente artigo é mostrar que no livro XI há uma relação entre tempo e vontade. Destaquemos, então, uma faceta do exercício narrativo: elaborá-lo e dispô-lo no interior do tempo fragmentário é um ato que excita o afeto humano (tanto o do narrador como o de seus leitores) e reorganiza os acontecimentos vividos no sentido de que eles conduzam ao deleite no louvor (comum) direcionado para Deus.

O processo de refazer a própria vida e narrá-la amorosamente envolve o reconhecimento da presença e da iniciativa divinas, bem como a mobilização da vontade humana. A ação divina é reconhecida e louvada através da confissão de louvor (ou confissão misericórdia divina); a situação humana, pela confissão de pecado (ou confissão da miséria humana). Assim, a vida do narrador ganha novo significado e é dinamizada pelo enaltecimento das ações divinas que socorrem os homens no tempo, e pelo reconhecimento das insuficiências humanas decorrentes do pecado. A narrativa humana expõe a miséria dos homens no seio de uma dinâmica e ganha, mediante a interferência da misericórdia divina, o horizonte da salvação. Se Agostinho narra suas misérias, é com a intenção de deleitar-se louvando Deus.

A centralidade do exercício da vontade com a intenção de amar Deus maximamente é axial na discussão agostiniana do tempo. A ênfase de Agostinho na relação entre vontade e tempo é notável nesta frase: "Já disse e direi: faço isto por amor ao teu amor" (AGOSTINHO, Confissões, XI, 1, 1; 2009, p. 27). ${ }^{5}$ E como é este amor? $\mathrm{O}$ amor humano por Deus envolve uma circularidade: $\mathrm{o}$ ato humano de amar Deus é causado pelo amor divino pelos humanos.

\begin{abstract}
"Por isso, te expomos nosso afeto ao confessar a ti as nossas misérias e as tuas misericórdias 'por sobre nós' (Salmo 33 (32), 22), para nos libertares totalmente, pois que tu o começaste, para deixarmos de ser miseráveis em nós e nos tornarmos felizes em ti; pois que nos chamaste (...). Foi assim que narrei muitas coisas para ti, as que pude e as que quis, pois tu quiseste primeiro, Senhor meu Deus, que eu te confessasse 'que és bom, que a tua misericórdia é para sempre' (Salmo 118 (117), 1)" (AGOSTINHO, Confissões, XI, 1, 1; 2009, p. 27)
\end{abstract}

Agostinho refere-se a um processo que se inicia com um ato divino, que desperta, pela experiência do deleite, o amor humano por Deus. Há, portanto, uma anterioridade causal do amor divino que se doa ao homem e estabelece o horizonte do amor humano por Deus, e isso é constatado em expressões como

\footnotetext{
${ }^{4}$ A inquietude natural do coração humano encontrará satisfação unicamente no deleite do repouso em Deus. Este é um dos temas fundamentais da filosofia agostiniana e das Confissões. Ver Confissões I, i, 1.

5 "iam dixi et dicam, 'amore amoris tui facio istuc."

6 "affectum ergo nostrum patefacimus in te confitendo tibi miserias nostras et misericordias tuas super nos, ut liberes nos omnino, quoniam coepisti, ut desinamus esse miseri in nobis et beatificemur in te, quoniam vocasti nos (...). ecce narravi tibi multa, quae potui et quae volui, quoniam tu prior voluisti ut confiterer tibi, domino deo meo, quoniam bonus es, quoniam in saeculum misericordia tua”.
} 
"tu começaste" ("coepisti”, AGOSTINHO, Confissões, XI, 1, 1; 2009, p. 27), "tu quiseste primeiro" (idem ibidem, conf. XI, 1,1).

A análise do prólogo do livro XI das Confissões mostra que, não obstante a desproporcionalidade entre Deus e o homem, Deus está presente no tempo sem ser determinado por características da temporalidade. Há uma presença divina no tempo que se faz perceber pelo exercício da narrativa humana amorosa. $\mathrm{O}$ amor humano por Deus é central na discussão sobre o tempo e é despertado por Deus no ser humano. Esse amor só encontra satisfação naquele que o despertou e move todos os homens em direção a deleitarem-se em um único louvor a Deus. Portanto, mostramos a pertinência do estudo sobre a relação entre tempo e vontade no texto que oferece a temática de todo o livro XI. Passemos, então, ao estudo dos modos dessa relação.

\section{A presença da Eternidade no tempo}

No livro XI das Confissões, a presença da eternidade no tempo é vivenciada pelo ser humano como desejo de Deus. Mas como criaturas temporais desejam a eternidade?

A eternidade é tematizada nos capítulos iniciais do livro XI das Confissões (XI, 1-17). Nesses capítulos, ela também é referida como o Princípio sempiterno mencionado no Livro de Gênesis 1,1 ("No princípio, Deus disse: 'faça-se a luz"”); como Filho, Cristo, mediador misericordioso; como Verdade, Virtude e Sabedoria; como o princípio, que é a luz que ilumina intimamente o ser humano, falando-lhe interiormente. Por que essa rede de sinônimos é indispensável para nossa investigação?

Ao comentar essa passagem do exórdio do Livro de Gênesis (Gn 1,1), Agostinho defende que, se o "Princípio" fez todas as criaturas, então ele as antecede. Entretanto, dado que o Princípio também é, por definição, eterno, seria rigoroso afirmar que esse Princípio existe antes das criaturas temporais? Sim e não. Não, se isso significar que esse Princípio (que é também Eternidade) existe cronologicamente antes de todas as criaturas terem sido criadas com o tempo. Argumentar desse modo pressupõe a inserção da Eternidade no curso do tempo, como se esta fosse cronologicamente a primeira em uma série. Contudo, se a Eternidade for temporalizada, deixará de ser eterna, o que desautoriza afirmar a anterioridade cronológica do Princípio. Porém, responde-se afirmativamente à questão acima, se a anterioridade for entendida em sentido causal, porque a Eternidade divina cria todas as criaturas (com o tempo) a partir do nada. Consequentemente, a existência das criaturas depende da anterioridade causal da Eternidade, mas não de sua precedência cronológica.

Além disso, Agostinho atribui uma série de sinônimos a Princípio, o que permite associá-los entre si e concluir, com Agostinho, que a anterioridade do Princípio se refere também à iluminação que os humanos recebem intimamente da luz da Eternidade. Trata-se da iluminação que os habilita a pensar sobre o tempo a partir de um parâmetro inequívoco. Neste sentido, para Agostinho, a própria meditação sobre o tempo se inicia a partir do contato humano com a eternidade, pois pela iluminação proveniente da eternidadeprincípio, os humanos (temporais) recebem acesso à eternidade divina. É a Eternidade (também designada por Agostinho como "palavra" e "misericórdia") que assegura essa possibilidade. Pensar sobre o tempo requer a iluminação da Verdade eterna, sempre atuante na intimidade humana.

A iluminação divina estabelece, portanto, uma relação com o entendimento humano. A única maneira de o entendimento temporal conceber a eternidade consiste em ser abarcado por ela, ao modo de uma aproximação em relação a algo que sempre esteve presente, mas do qual o entendimento humano se ausentava. Tal processo se aproxima mais de um desprendimento de algumas categorias inadequadas do entendimento humano do que de algo por ele produzido. Como veremos, a tentativa humana de falar sobre a eternidade será exemplificada pelo canto do qual se retiram as palavras, por serem inadequadas 
para expressar aquilo que há de ser cantado. A relação humana com a eternidade se faz tanto pelo desejo como pelo conhecimento.

\section{A medição do tempo}

Um dos dados mais imediatos acerca da relação humana com o tempo é o fato de que o tempo é medido e sentido pelos humanos. Isso mostra que a medição temporal é passível de ser conhecida por quem mede, e não "objetivamente". E como se dá a mensuração do tempo? Defenderemos que ela envolve a atenção daquele que o mede, isto é, medir o tempo é também medir a duração da atenção da alma. Esta atenção, por sua vez, compreende a experiência (ou sensação) humana do tempo. E como sentimos o tempo?

Sentimos o tempo vindo do futuro, atravessando o presente e se tornando passado. Mas onde isso ocorre? Para encaminhar essa discussão, Agostinho descarta que a sucessão temporal permaneça como algo que conserve seus momentos sucessivos na exterioridade. Com efeito, o autor questiona se o futuro, o presente e o passado existem como realidades exteriores e independentes do ser humano. Ao considerarmos o tempo futuro, é evidente que ele ainda não existe e, portanto, não é real em si mesmo. No entanto, temos uma expectativa em relação ao futuro, esta sim presente e real como sensação anímica. E quanto ao passado? Este se refere ao que não existe mais externamente, pois já passou e, portanto, o que é passado inexiste em si mesmo. Não obstante, conhecemos o que passou pois o conservamos presente em nossas memórias, ou seja, o passado é a memória presente daquilo que passou. Finalmente, indagamos se o presente existe. Até mesmo esta afirmação se mostra falsa, pois, ao tentarmos reter a existência do tempo presente (do instante), ele escorrega para o passado, que já deixou de existir. Portanto, tampouco o presente existe exteriormente. Contudo, o presente conserva-se na alma.

Se o tempo exterior é tão elusivo, como explicar o fato de ele ser medido? Agostinho responde a esta dificuldade referindo os três tempos à presença interior. Apenas na interioridade humana o futuro, o presente e o passado conservam alguma realidade. Portanto, nesse sentido, o tempo será considerado como algo interior, cuja realidade e presença são percebidas pela alma. A interiorização e psicologização do tempo serão fundamentais para considerarmos a relação entre tempo e vontade.

Para Agostinho, tempo e memória são interdependentes. Ela é o grande receptáculo da alma, na qual se encontra guardado tudo que é conservado na interioridade humana. Seguindo essa linha de raciocínio, o passado é entendido por Agostinho como a presença daquilo que já ocorreu e passou (fora), mas que resta presente na memória (dentro). O futuro existe tão somente na interioridade humana e é uma expectativa elaborada a partir de conteúdos presentes na memória. Enfim, o presente é definido como olhar da alma. Os três tempos (passado, presente e futuro) são explicados por Agostinho nos seguintes termos:

\footnotetext{
"Isto agora é límpido e claro: nem as coisas futuras existem, nem as coisas passadas, nem dizemos apropriadamente 'existem três tempos: o passado, o presente e o futuro'. Mas talvez pudéssemos dizer apropriadamente 'existem três tempos: o presente das coisas passadas, o presente das coisas presentes, o presente das coisas futuras. Pois os três estão de alguma maneira na alma e eu não os vejo em outro lugar: o presente das coisas passadas é a memória, o presente das coisas presentes é o olhar, o presente das coisas futuras é a expectativa." (AGOSTINHO, Confissões, $\mathrm{XI}, \mathrm{xx}, 26 ; 2009$, p. 43) ${ }^{7}$
}

Desta passagem das Confissões, concluímos que toda experiência temporal humana depende de uma referência interior. Mas se Agostinho interioriza o tempo, como explicar o fato de medirmos e comparamos as durações dos tempos? Ora, não se pode fixar o curso do tempo, pois o tempo exterior é definido por

\footnotetext{
7 "Quod autem nunc liquet et claret, nec futura sunt nec praeterita, nec proprie dicitur: tempora sunt tria, praeteritum, praesens et futurum, sed fortasse proprie diceretur: tempora sunt tria, praesens de praeteritis, praesens de praesentibus, praesens de futuris. Sunt enim haec in anima tria quaedam et alibi ea non video, praesens de praeteritis memoria, praesens de praesentibus contuitus, praesens de futuris exspectatio."
} 
sua fugacidade e está sempre passando. Assim, é impossível medir o tempo a partir de uma duração que lhe sirva de medida padrão. Não há como comparar duas durações de tempo à maneira de dois corpos extensos e com comprimentos diferentes. Entretanto, o tempo não tem extensão porque infixável (não se pode retê-lo de modo a demarcar espacialmente seu começo e seu fim), por isso o tempo é localmente inextenso. Logo, se exteriormente o tempo sempre passa, não há medida de tempo que possa servir de parâmetro para contar outros tempos. Então, de que modo encaminhar a questão sobre a medição do tempo? Se Agostinho se refere ao tempo como experiência humana pertinente à memória, portanto à interioridade, então o tempo existe internamente, mas como medir algo interior? Como mensurar algo sem extensão corpórea?

Em defesa de que a medida do tempo não se refere à extensão de algo exterior e corpóreo, Agostinho assevera que, quando se mede o tempo, mede-se a distensão da atenção da alma. Em outras palavras, o tempo dura para nós o quanto dura nossa atenção, e é ela que medimos. Nesse sentido, Agostinho define o tempo como distentio animi (distenção da alma), o que requer esclarecimento porque o sentido mais usual de distentio é corporal e a alma, na filosofia de Agostinho, é incorpórea.

\section{Distentio animi}

Para compreender o significado agostiniano de distentio animi, averiguemos primeiramente o significado de distentio. No Oxford Latin Dictionary, o curto verbete "distentio" consta de duas definições, ambas esclarecedoras da questão do tempo. O primeiro significado divide-se em dois aspectos complementares: (1) exteriorização enquanto prolongamento para fora, distensão ("a stretching out"); ocupação (ocupar, ir habitar, acampar). ${ }^{8}$ Assim, primeiramente distentio é exteriorização, ocupar, habitar algo fora. Conforme o segundo significado, distentio é inchaço ou distensão corporal, por exemplo, estomacal ou do braço; diz respeito ao prolongamento antinatural para fora devido a alguma tensão ou doença interior, e que leva a uma deformação.

Distentio é também a forma participial do verbo distendo, tal como "distendido" em português. No referido dicionário, o verbo distendo ${ }^{9}$ reapresenta os significados mencionados acima com acréscimos: "to stretch asunder" (separar em partes, fragmentar, separar distanciando ${ }^{10}$, dividir, separar, afastar; ter determinada extensão (ocupar uma determinada medida de área); distrair, dirigir-se para fora, dispersar-se; distender por desgaste, a exemplo de um músculo. Distendo é também um composto de "dis" e "tendo"; e tendo (tender) também denota ter vontade, almejar, voltar-se para, inclinar-se a, tender a, ansiar, mudar o curso em outra direção, dedicar-se a algo, esforçar-se, insistir, persistir.

Essa gama semântica sugere que a distentio animi (distentio da alma), com a qual Agostinho define o tempo, pode ser interpretada como o processo de a alma voluntariamente habitar (ocupar) o mundo exterior. A distentio animi ocasiona um desgaste em razão de um anseio antinatural e persistente. Trata-se de uma inclinação para fora que causa uma cisão, uma separação na alma, dissipação (fragmentação) e alheamento, afastando-a de seu interior e apartando-a do lugar onde ela poderia encontrar Deus. A distentio aninmi comporta, além dessa fratura anímica, uma dispersão da vontade, gerando, assim, dispersão, divagação, desgaste e fragmentação enfraquecedora da vontade em muitos quereres. Ela se refere à sobrecarga da alma com preocupações e solicitações oriundas de uma vontade desordenada porque busca satisfazer seu desejo fundamental de Deus dispensando-se com coisas temporais e mutáveis. A distentio refere-se

\footnotetext{
${ }^{8} \mathrm{http}: / /$ www.perseus.tufts.edu/hopper/morph?l=distentio\&la=la\#lexicon .

9 http://www.perseus.tufts.edu/hopper/text?doc=Perseus\%3Atext\%3 A 1999.04.0059\%3 Aalphabetic+letter\%3DD\%3Aentry+group\%3D45\%3Aentry\%3Ddistend

${ }^{10} \mathrm{https}$ ://www.merriam-webster.com/dictionary/asunder
} 
ao apego da vontade às coisas temporais e impermanentes como se estas pudessem corresponder ao desejo humano de felicidade, verdade e estabilidade. Isso leva o ser humano a desfrutar desmedidamente momentos passageiros de satisfação.

Entretanto, a concepção agostiniana de distentio animi nem sempre é negativa e também conota o alargamento da alma e seu deleite em Deus. Analisemos a referência de Agostinho a Josué 10:12:

"Pois, quando, a pedido de alguém, o sol parou para que um combate vitorioso se completasse, o sol ficou parado, mas o tempo prosseguiu. Com efeito, através do espaço de tempo que lhe bastou, aquela batalha ocorreu e acabou. Vejo então que o tempo é certa distensão." (Confissões, XI, xxii, 30; 2009, p. 47) ${ }^{11}$

No Livro de Josué, Deus detém o curso do Sol e da Lua, imobilizando-os para uma batalha virtuosa ser completada. É notável que, no contexto do livro XI das Confissões, essa passagem produza uma guinada no texto. Até esse ponto, Agostinho refutava as teorias que definiam o tempo a partir dos movimentos solares. A partir dessa menção a Josué, Agostinho não deixa dúvidas sobre quem comanda o tempo: Deus, criador e senhor do tempo. Deus pode inclusive parar o tempo cronológico, parar o curso dos astros, para que os seres humanos ajam na história em uma outra temporalidade. $\mathrm{O}$ intuito dessa atitude divina, segundo o texto de Josué, é viabilizar que se complete uma guerra difícil, porém justa (porque comandada por Deus). Mas como entender essa referência no livro XI das Confissões?

Em seu livro Knowing God and the Soul, Roland Teske enfatiza que, nas escrituras, algumas categorias são atribuídas a Deus sem que isso implique a categorização do próprio ser divino. Teske esclarece que, por exemplo, quando as escrituras mencionam que Deus mudou sua ação, tomando alguma iniciativa (como deter o curso dos astros, eu acrescentaria), isso não significa que Deus tenha mudado e, portanto, que ele seja mutável. Em vez disso, Agostinho defende a imutabilidade divina e sustenta que tal mudança diz respeito à mudança da perspectiva humana em relação ao Deus imutável. Nesse contexto, proclamar que Deus deteve o curso dos astros pode ser interpretado como uma mudança ocorrida na relação do ser humano com a eternidade, em razão de o ser humano ter passado a agir de acordo com sua própria vontade, que passou a querer realizar algo justo, uma batalha que Deus comandara. Assim, há um certo "tempo da justiça" que reflete aos justos outra vivência e percepção do tempo cronológico (o tempo dos astros), que parou para aquele homem agir por sua vontade, consonante com a vontade divina.

Em Josué, narra-se que Deus deteve o curso solar e lunar durante quase um dia inteiro para que uma batalha fosse completada. $\mathrm{O}$ texto bíblico de Josué indica o contexto da passagem mencionada: trata-se de uma batalha virtuosa e que deveria ser completada por ser justa. A justiça confere virtude a tal batalha que, embora comandada por um ser humano, havia-lhe sido ordenada por Deus. Josué estava motivado por sua verdadeira vontade, a qual coincidia com a divina, obedecendo-lhe. ${ }^{12}$ Este amoldamento da vontade humana à divina leva o ser humano a experimentar uma temporalidade mais expansiva e perene. Josué obteve, então, a vivência de outra temporalidade: aquela governada por um desejo divino e que culmina no contentamento interior e mais largo, a delectatio.

O direcionamento do amor humano por e para Deus provoca uma temporalidade orientada para a manifestação de Deus no tempo. Josué, ao colocar sua vontade a serviço da vontade divina e combater uma guerra justa, teve a experiência de o sol ter sido parado, pois a temporalidade que passou a vigorar não era mais aquela mensurável pelo movimento astral. O tempo da batalha passou a servir à interiorização e à

\footnotetext{
11 "quia et cuiusdam voto cum sol stetisset, ut victoriosum proelium perageret, sol stabat, sed tempus ibat. per suum quippe spatium temporis, quod ei sufficeret, illa pugna gesta atque finita est. video igitur tempus quandam esse distentionem."

${ }^{12}$ Quanto à vontade humana se submeter à vontade divina e tornar-se mais livre e ordenada, recomenda-se o estudo da dissertação de mestrado de Rodrigo F. Sote que versa sobre a situação da vontade humana a partir da noção de ordo amoris no contexto das Confissões de Agostinho (SOTE, 2017).
} 
elevação da vontade de Josué e ocasionou seu ultrapassamento e a experiência da grandeza supereminente de Deus, o Deus-Justiça-Eternidade. Por isso, pareceu aos seres humanos, que medem o tempo pelos astros, que Josué fez algo impossível de ser praticado por um humano mortal. ${ }^{13}$

No Antigo Testamento, as conquistas bélicas de Josué são comemoradas com uma expressão sonora de alegria e vitória, o jubilus (Êxodo 32, 17). Quanto ao jubilus, Gianfranco Ravasi explica que "na bíblia, os cantos marciais tinham uma veia religiosa porque eram ligados à guerra santa (RAVASI, 1992, p. 86). ${ }^{14}$ Ainda conforme Ravasi, esses cantos sagrados de guerra são mencionados numa aclamação "famosíssima de Josué ('Sol, pare sobre Gibeom e você, lua, sobre o vale de Aijalom')” (idem ibidem). ${ }^{15}$ Josué, segundo o comentador, traz uma "oscilação entre o canto militar e o canto litúrgico" (idem, p. 87). ${ }^{16}$ Ora, essa passagem é precisamente aquela mencionada por Agostinho no livro XI das Confissões. Embora o texto de Agostinho não mencione o aspecto de júbilo característico das conquistas bélicas de Josué, o texto do livro XI das confissões parece aludir ao jubilus, agora ainda de modo sugestivo, posteriormente de maneira mais pronunciada.

Portanto, a menção a Josué convoca a memória do jubilus e do deleite coletivo em louvar Deus, os quais foram declarados, em Confissões, XI, 1, 1, a meta e o motivo da escritura da meditação sobre o tempo. Essa interpretação está de acordo com o que defendemos antes, a saber, (1) que o significado do tempo diz respeito a como a alma direciona seu desejo fundamental de Deus; (2) que, quando a alma volta seu amor para a exterioridade (vide o primeiro sentido de distentio), o tempo lhe foge e ela se desgasta; e (3) que, se o desejo humano se dirige para Deus (acessível ao homem através da interioridade) e ao aproximar-se de Deus, o ser humano se dirige para onde a Eternidade fala enquanto Princípio, Palavra e Verdade. Considerando esses três pressupostos, pensamos que as ações e reflexões humanas colaboram para a experiência de uma expansão interior (dilatação) ${ }^{17}$, uma sorte de aumento do "espaço" da alma. Espaço da alma, aqui, denota uma ampliação ao revés da disposição dispersiva da vontade. O prazer oriundo da distentio prioriza exaustiva e apressadamente as coisas temporais. Em contraposição, o deleite provém e produz tantas ações virtuosas que, aos olhos de outros, pode parecer que o tempo parou para que o virtuoso triunfasse.

O desgaste e o deleite anímicos dizem respeito à experiência que a alma tem de sua vontade no tempo. Nesse sentido, a magnitude e o valor do tempo não são dimensionados quantitativamente, senão em termos qualitativos. O tempo do deleite é menos fugaz e menos dispersivo. $\mathrm{O}$ "espaço" correspondente a esse tempo é mais largo e intenso. $\mathrm{O}$ tempo do deleite é vivido, tanto quanto possível, orientado para a eternidade. Nessa dimensão temporal e espiritual, o tempo admite uma velocidade ditada, experimentada pela vontade humana virtuosa alinhada e ampliada pela vontade divina. A defesa de uma temporalidade do deleite interior e espiritual recebe um argumento decisivo quando Agostinho observa que não apenas o tempo é mensurável, mas também o silêncio.

\footnotetext{
${ }^{13}$ Segundo Gianfranco Ravasi: "Nella Bibbia i canti marziali hanno spesso una venatura religiosa perchè erano connesi a la guerra santa" (p. 86). Os cantos sagrados de guerra são mencionados numa aclamação "famosissima di Giosuè ("Sole, fermati in Gabaon et tu, luna, sulla valle di Aialon" - Josué 10,12) (p. 86). Essa passagem é precisamente a mesma mencionada por Agostinho. Para Ravasi, há, em Josué, uma "oscillazione tra canto militare e canto liturgico" (p. 87). Portanto, interpretamos que, nessa passagem das Confissões, Agostinho refere-se a duas características do canto mencionado no texto de Josué, a saber, um canto simultaneamento bélico e sagrado, chamado de jubilus.

14 "Nella Bibbia i canti marziali hanno spesso una venatura religiosa perchè erano connesi a la guerra santa."

15 “... famosissima di Giosuè ('Sole, fermati in Gabaon et tu, luna, sulla valle di Aialon')”.

16 "oscillazione tra canto militare e canto liturgico".

${ }^{17} \mathrm{O}$ significado de "dilatação" aqui empregado filia-se à apresentação de Jean-Louis Chrétien em La Joie Spatieuse, cujo primeiro capítulo, "Saint Augustin et le grand large du désir" (pp. 33-63) é dedicado aos usos de "dilatatio" nos escritos de Agostinho.
} 
O silêncio é medido em razão do som, ou seja, é medido como se houvesse som, mas abstraindo-se o som. Isso indica que medir o silêncio é medir a duração do som na existência exterior deste. Ora, se a medição do silêncio for dimensionada em termos de extensão espacial, então tal "extensão" inexistente exteriormente deverá ser entendida enquanto uma extensão que acontece na alma, distensão esta que se situa em um "lugar" interior e com "extensão" anímica. Quando o silêncio é medido, mede-se a alma ocupando o que não tem sonoridade, como se ela mesma fosse a sonoridade. Nesse sentido, mede-se o movimento de a alma ocupar o tempo. Trocando em miúdos, o exemplo dado por Agostinho sobre a medição do silêncio mostra que isso equivale a medir a duração do tempo com base na ocupação que a alma faz de sua própria existência (com pensamentos e vontades).

Outro exemplo fornecido por Agostinho sobre o alargamento da alma refere-se ao ato de cantar. $\mathrm{O}$ ato de cantar, e não o movimento circular dos astros e dos tornos dos oleiros, é escolhido como exemplo paradigmático para explicar o tempo. Se o entendimento sobre o tempo é centrado na discussão sobre a alma, então o que pode ser afirmado acerca dos três tempos (presente, passado e futuro)? De que maneira existem? O exemplo selecionado por Agostinho é o canto, por quê? Para Agostinho, o canto ilustra o que ocorre com "todas as ações do ser humano" no tempo (Confissões, XI, xxviii, 38; 2009, p. 53). O filósofo apresenta o seguinte experimento mental:

"Vou entoar uma canção que sei. Antes de iniciar, minha expectativa se estende totalmente, mas quando começar,
tanto quanto eu tiver tirado da expectativa, também minha memória se estende, e a vida desta minha ação se
distende na memória (em razão do que cantei) e na expectativa (em razão do que cantarei). Minha atenção também
está ali, presente, pela qual o que era futuro é arrastado para tornar-se passado. E quanto mais isso acontecer e
acontecer, a expectativa será abreviada e a memória será prolongada, até que toda a expectativa seja consumida,
quando toda a ação terminada houver transitado para a memória. E o que ocorre na canção toda, também ocorre
nas suas partículas singulares, e o que ocorre nas partículas singulares, também ocorre na ação mais longa, da qual
talvez aquela canção seja uma partícula, e o mesmo em toda a vida do ser humano, das quais são partes todas as
ações do homem, e o mesmo em todo o século dos 'filhos dos seres homens (Salmo 30,20), das quais são partes
todas as vidas dos homens." (AGOSTINHO, Confissões. XI, xxviii, 38; 2009, pp. 52-53)

Agostinho propõe que seja considerado alguém que está prestes a entoar um canto já conhecido. No decorrer desse cantar, segundo Agostinho, ocorre interiormente a presença concomitante dos três tempos na alma do cantor. Com efeito, enquanto canta, esse alguém sabe tanto o que já cantou, como aquilo que ainda falta ser cantado. E, distendido entre duas atenções diversas, esse mesmo alguém também detém a atenção voltada para o presente, quando produz o som do canto. Todos esses tempos (o canto passado, presente e futuro) pressupõem que haja na memória a lembrança do canto necessária à produção dos três. Assim, quando o cantor profere um som no presente, esse som transita do futuro (como algo que ainda deve cantado) para o passado (como aquilo que já foi cantado). Cantar é, portanto, uma atividade complexa em que a alma precisa estar atenta aos três tempos presentes na sua interioridade como as três atenções da alma. Por isso, estranhamente, cantar significa estender a atenção anímica simultaneamente em passado, presente e futuro, produzindo uma coexistência interna desses tempos. O canto, nesse sentido, estende internamente a alma em tensões de direcionamentos opostos, dilatando-a e deleitando-a.

Contudo, a simultaneidade dos três tempos é impossível no mundo exterior. Na exterioridade, um evento futuro, por definição, não está acontecendo agora (não é presente) nem ocorreu (tampouco é passado). O que ocorre presentemente está acontecendo agora e não pode ser futuro (pois o futuro ainda

\footnotetext{
18 "dicturus sum canticum quod novi. antequam incipiam, in totum expectatio mea tenditur, cum autem coepero, quantum ex illa in praeteritum decerpsero, tenditur et memoria mea, atque distenditur vita huius actionis meae in memoriam propter quod dixi et in expectationem propter quod dicturus sum. praesens tamen adest attentio mea, per quam traicitur quod erat futurum ut fiat praeteritum. quod quanto magis agitur et agitur, tanto breviata expectatione prolongatur memoria, donec tota expectatio consumatur, cum tota illa actio finita transierit in memoriam. et quod in toto cantico, hoc in singulis particulis eius fit atque in singulis syllabis eius, hoc in actione longiore, cuius forte particula est illud canticum, hoc in tota vita hominis, cuius partes sunt omnes actiones hominis, hoc in toto saeculo filiorum hominum, cuius partes sunt omnes vitae hominum."
} 
inexiste), nem sequer passado (porque não deixou de acontecer); e, enfim, quanto ao passado, se algo passou e já passou, ele não pode ser identificado com o futuro (que ainda não aconteceu e acontecerá), tampouco com o presente (dado que já terminou). Assim, se os três tempos se excluem mutuamente na exterioridade, o exemplo agostiniano do canto mostra como eles são imbricados na interioridade e os três dependem de uma presença na memória. Há, então, outro regime temporal da alma observado quando ela se atém aos seus próprios movimentos. Essa temporalidade do espírito guarda outra regência, outra velocidade, outro sentido.

\section{Deus creator omnium}

O canto selecionado por Agostinho para explicar o que é o tempo para a alma merece destaque. Tratase do verso inicial de um hino composto por Ambrósio de Milão: "Deus creator omnium", que significa "Deus criador de tudo". Minha hipótese sobre a razão de Agostinho ter selecionado esse verso será desenvolvida em quatro etapas: (1) a consideração puramente métrica do verso Deus creator omnium, (2) a identificação de elementos do jubilus nesse canto, (3) a apreciação do significado das palavras desse hino e (4) a ponderação sobre sua exemplaridade em relação à vida humana.

Primeiramente, Agostinho afirma que, para se declamar Deus creator omnium, deve-se respeitar a métrica de jambo desse verso, ou seja, oito sílabas alternadas entre breves e longas ("dè--uss crè-ā-tor ō-mnú-ūm", Confissões, XI, xxvii, 35). Mas como cantá-lo? Proferindo suas sílabas, comparando-as, para que umas contem a metade ou o dobro das outras.

Portanto, a primeira consideração de Agostinho sobre tal verso volta-se apenas para a duração das sílabas do canto, separando e abstraindo o significado de suas palavras.

Notavelmente, na dinâmica do livro XI, o hino em questão é motivo da comparação entre a duração das sílabas e serve à defesa da interioridade do tempo. A medição da duração das sílabas, como visto anteriormente, não se realiza na exterioridade, com paradigmas de extensão local. Não há como comparar a duração das sílabas de um canto como se elas pudessem ser afixadas lado a lado, qual estacas, pois o tempo não é algo cujas extremidades (início e fim) possam ser estabilizadas. Contudo, a comparação da duração das sílabas ocorre no canto. Mas como? Para Agostinho, a negação do parâmetro de medição corporal para o tempo direciona a resposta para a interioridade, domínio da alma.

Apenas na interioridade (na memória) atribui-se alguma estabilidade ao tempo, ainda que a própria memória seja mutável e não disponha todos os seus conteúdos simultaneamente à consciência. Na memória, ou seja, na interioridade, a duração das sílabas de um canto a ser produzido encontra uma métrica, pois a memória atribui duração ao que ela se conserva. Isso é provado por Agostinho no passo seguinte de sua argumentação, a saber, a medição do silêncio (Confissões, XI, xxvii, 36).

A alma canta em silêncio antes de cantar sonoramente, antecipando o canto dentro de si para, a partir de então, produzir o som. Esse canto interior requer, na memória, tanto a presença daquilo que a alma quer proferir no futuro, bem como do que ela sabe estar produzindo e lembra já ter cantado. Nesse canto interior e anterior, a atenção da alma se expande em três direções no íntimo, e produz a vivência da dilatação de sua própria atenção em três tempos. Como afirmamos anteriormente, há um presente interior mais amplo $\mathrm{e}$ que acolhe o presente, o passado e o futuro. Essa temporalidade ampliada e interior não ocorre no exterior.

O canto interior, se for direcionado para Deus e animado pela intenção de louvá-lo, promove o verdadeiro alívio da fadiga da alma. A alma se desgasta por se apegar inadequadamente à exterioridade. No entanto, cantando, a alma se torna menos propensa a exagerar seu prazer em relação à sua exteriorização, o qual é útil se bem equacionado. $\mathrm{O}$ exemplo do canto indica a possibilidade de a alma estar mais atenta ao que ela 
mesma guarda e produz, e isto é menos transitório relativamente ao tempo exterior. Nesse "lugar interior sem lugar" ("interiore loco, non loco", AGOSTINHO, Confissões, X, ix, 16), ou seja, na memória, a alma gradualmente pode aproximar-se de seu âmago, "onde" a eternidade lhe fala.

Nossa segunda observação acerca da escolha de Agostinho por esse canto concerne à identificação de elementos do jubilus neste canto. Com efeito, ao considerar este canto em seu aspecto puramente métrico (abstraindo-lhe o significado), Agostinho destaca o caráter melismático (sem palavras) desse canto. Se assumirmos essa atitude como programática, tendo em conta que o canto melismático também era referido como jubilus, então cantar Deus creator omnium promove a abertura humana à presença da eternidade. Conforme Lorenzo Mammì:

\begin{abstract}
"A comunidade paleocristã conheceu uma forma de canto em que o descolamento entre música e texto é programático: o jubilus, canto sem palavras, a mais primitiva das formas melismáticas que constituirão, mais tarde, a glória e o luxo da melodia cristã. O jubilus parece ser uma conquista estética do cristianismo. O pensamento clássico desconhece a ideia de um canto que dispense as palavras. $\mathrm{O}$ canto melismático é estranho também à tradição judaica." (MAMMì, 2017, pp. 328-329).
\end{abstract}

Mammì reporta-se ao canto sem palavras e não à consideração da métrica do verso. Nós tomamos de empréstimo essas considerações sobre o canto melismático e as empregamos na análise do canto de Deus creatir omnium, do qual Agostinho inicialmente considera apenas a reprodução métrica. Com efeito, quando Agostinho considera apenas a parte sonora desse verso, e essa separação caracteriza o jubilus, há uma associação entre o canto desse verso e o jubilus.

Finalmente, consideremos a escolha de Agostinho por Deus Creator omnium, um hino cujo título (ou primeiro verso) significa "Deus criador de tudo". A razão desta escolha não é explicitada por Agostinho, mas a força desse significado merece consideração quer devido ao caráter performático de sua linguagem, quer pelo significado da letra da estrofe.

Esse verso retoma a performatividade da linguagem, já mencionado no início desse artigo. Com efeito, aqui, linguagem personifica e é animada por seu significado, enquanto linguagem viva, linguagem de louvor animada pelo amor a Deus e, por isso, capaz de provocar naquele que a recita a vivência do significado do verso.

O verso inicial desse hino evoca o hino completo, assim, a continuação do hino serve para entendermos ao quê remetia esse primeiro verso ao leitor das Confissões na época de Agostinho. O hino de Ambrósio canta:

\footnotetext{
"Deus creator omnium/ Polique rector vestiens / Diem decoro lumine / Noctem soporis gratia / Artus solutus ut quies / Reddat laboris usui / Mentes fessas allevet / Luctusque solvat anxios (...)” (Apud MAMMÌ, L., 2017, p. 340, n. 28$)$.
}

A letra do hino atribui uma dependência de todas as criaturas a Deus, em diversos sentidos. Além de ser o criador único, Deus é referencial para tudo que existe e não é Deus (suas criaturas). Deus rege os movimentos celestes, confere a beleza da luz do dia, promove o descanso revigorante do sono, oferece repouso (quies) à fadiga corporal e espiritual e dissolve a angústia da morte. O hino menciona a ambiguidade da experiência humana através de características opostas, por exemplo, Deus confere descanso e repouso corporal e espiritual em compensação à fadiga, ao cansaço e à angústia da existência. $\mathrm{O}$ desgaste humano (e sua angústia) ${ }^{19}$ é remediado pela vivência da centralidade divina, a qual é menos uma atividade humana que busca acréscimos de autoria humana, e mais uma entrega para essa presença divina, íntima, embora não contida no ser humano, e que requer uma certa "dissolução". As ações que revigoram são ações divinas e não humanas, capazes de dissolver a angústia da morte, de prover o sono reparador (o ser humano é

${ }^{19}$ Em latim, angustus significa apertado, estreitado, não espaçoso, comprimido, contraído. 
menos voluntariosos no sono), de reger tudo com beleza (o ser humano é regido e opta por harmonizar-se ou não ao ritmo universal, do qual ele não é o autor) e de oferecer uma sorte de descanso que não pode ser proporcionada pelo ser humano, posto que requer seu transbordamento. Esse movimento, a meu ver, refere-se ao contentamento expansivo e revigorante típico do júbilo, em Josué, referido em Agostinho tanto no exemplo de Josué como, agora, no canto de Deus creator omnium.

Deus creator omnium retoma, assim, a dicotomia entre deleite revigorante e angústia desgastante. $\mathrm{O}$ deleite é júbilo, expressão da alegria da alma que ama e conduz sua vida motivada e voltada para o amor divino. Ademais, como Deus é o criador e aquele que confere ordem ao mundo, o júbilo, então, manifesta também harmonia humana com o cosmos.

Em contrapartida, há outro modo de a alma viver. Trata-se de uma vida desviada de seu destino natural, por isso, per-vertida. Nessa situação, o desejo fundamental humano de repouso em Deus não é alterado, posto que respeita à natureza humana tal como estabelecida por Deus. No entanto, devido ao pecado original e às escolhas pelo desfrute de coisas inferiores a Deus, tal desejo não encontra realização. Em vez disso, o desejo humano de alargamento, de amar Deus, é transferido para realidades inferiores e acaba sendo diminuído e colhendo insatisfações através de prazeres precários.

Portanto, no livro XI das Confissões, o hino ambrosiano ecoa a dicotomia entre duas orientações da vontade da alma: (1) o deleite revigorante do direcionamento da alma que se volta para Deus-eternidade; (2) e a fadiga da alma que vive em função de prazeres precários, que provêm das criaturas-temporais. A diferença entre esses dois tipos de prazer, embora conceitualmente clara, não se pauta nas coisas amadas, e sim por como são amadas: as criaturas devem ser amadas na medida em que favorecem a fruição de Deus, e não como finalidade do amor.

Finalmente, o quarto apontamento sobre o exemplo do canto diz respeito à conclusão que Agostinho tece: o que acontece com o canto também se passa na vida humana, quer em cada parte (segundos, minutos, horas, dias, acontecimentos), quer na sua totalidade (a vida de cada ser humano); e até mesmo na totalidade das vidas humanas (e aqui há a universalização absoluta anunciada no prólogo no livro XI). O canto, como a vida, é pensado em termos de durações ou tempos. O canto, como a vida, pode ser jubilante, embora a aquisição perfeita da felicidade plena e estável seja impossível durante a existência no mundo, mas não após o juízo final. E mesmo que futura, ela já é presente em expectativa. Embora a felicidade inesgotável só advenha no pós-morte, ela já está presente ao modo do Deus-Princípio, e o ser humano pode ter experiências de deleite nesta vida, ainda que elas sejam passageiras. Esse deleite acompanha a dilatação interior da alma, e produz uma outra qualidade de tempo, virtuoso, em que a alma, ao invés de se desgastar buscando manter o desfrute daquilo que é impermanente por definição, apresenta-se para aquela presença interior, revigorante e que dissolve a fadiga. Ao referenciar o tempo à Eternidade, Agostinho pensa o tempo como lugar possível para a existência virtuosa e que, embora temporal, sabe-se direcionada à eternidade.

\section{Conclusão}

Agostinho pergunta "o que é o tempo?" no contexto de uma filosofia eudaimônica. O tempo não é abordado qual uma substância. Em vez disso, a questão sobre o tempo respeita ao vínculo que a vontade humana estabelece com Deus e com o mundo, bem como à presença divina. $\mathrm{O}$ tempo ganha um sentido duplo. Se o tempo é preenchido pelas exigências da vontade dirigida ao prazer dispersante, angustiante e desgastante, ele é, então, o tempo da infelicidade. Se o tempo for preenchido pela vontade que intenta exercitar seu amor por Deus a ponto de chegar ao deleite em louvá-lo, então o tempo é preenchido pela confissão das faltas humanas e pela confissão do socorro divino. Neste segundo modo de viver o tempo, 
encontra-se a possibilidade de o homem reinterpretar as próprias misérias e inseri-las na narrativa da misericórdia divina. $\mathrm{O}$ tempo do homem que exercita seu afeto em direção a Deus deseja a satisfação do amor fundamental que governa a vida humana e possui momentos de deleite interior.

Portanto, a experiência humana do tempo manifesta o encaminhamento dos amores humanos para Deus ou não, a ponto de o significado e a percepção do tempo acompanharem o sentido que a alma escolhe para sua vida.

Nesse artigo, recuperei parcialmente o que havia sido discutido em "O tempo, espelho da alma" (AYOUB, 2010), acrescentando, além de outros contornos, considerações sobre jubilus e as interpretações sobre a menção de Agostinho a Josué e sobre a escolha de Agostinho exemplificar o canto do hino Deus creator omnium.

\section{Referências bibliográficas:}

Fontes primárias:

AURELII AUGUSTINI. 1990. Confessionum libri XIII. Ed. L. Verheijen. In: Brépols: Turnhout ("Sancti Augustini Oprera, Series Latina", 27).

. 1992. The Confessions of Augustine: An electronic edition. Edição, tradução e notas de J. J. O’Donnel. Disponível em: http://www.stoa.org/hippo/. Acesso: 12 out. 2018. ${ }^{20}$

1992. Confessions. Translation by Henry Chadwick. Oxford/New York: Oxford University Press.

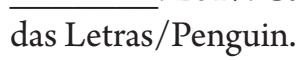

2017. Confissões. Tradução, introdução e notas de Lorenzo Mammì. São Paulo: Companhia

. 2009. “Confissões, livro XI”. Tradução, introdução e notas de Cristiane Negreiros Abbud

Ayoub e Moacyr Novaes. In: MARÇAL, J. (org.). Antologia de textos filosóficos. Curitiba: SEED - Paraná.

.2012. The Confessions. Introdução, tradução e notas de Maria Boulding. 2a ed. New York: New City Press. ("The Works of Saint Augustine: A Translation for the 21st Century", 1)

. 1982. De uera religione. Tradução francesa de J. Pégon e G. Madec. Paris: Desclée de Brower ("Bibliothèque Augustinienne", 8)

Fontes secundárias:

AYOUB, C. N. A. 2010. O tempo, espelho da alma. [Online]. Revista Cult 153: 63-65. Disponível em https://revistacult.uol.com.br/home/o-tempo-espelho-da-alma/. Acesso em 12/02/2020.

CALAHAN, J. F. 1679. Augustine and the Greek Philosophers. Philadelphia: Villanova University Press.

CHRÉTIEN, J.-L. 2007. La Joie Spatieuse: essai sua la dilataion. Lonrai: Les Éditions de Minuit.

20 Citamos o texto latino desta edição por incluir marcações (aspas e pontuação) ausentes na edição crítica de Verheijen. Quanto às palavras e suas sequências, ambas as edições são iguais. 
GIRAUD, V. 2014. Delectatio interior plaisir et pensée selon Augustin. Paris. Les Études philosophiques, 109/2, 201-217.

LEWIS, C. T.; SHORT, C. 1879. A Latin Dictionary. Oxford: Clarendon Press. Disponível em http:// www.perseus.tufts.edu/hopper/text?doc=Perseus\%3Atext\%3A1999.04.0059\%3Aentry\%3Ddistentio. Acesso em: 16 jan. 2020.

MAMMÌ, L. 1998. Santo Agostinho, o tempo e a música. Tese (Doutorado). Faculdade de Filosofia, Letras e Ciências Humanas, da Universidade de São Paulo.

2017. A fugitiva: ensaios sobre música. São Paulo: Companhia das Letra.

NOVAES, M. 2007. A razão em exercício, estudos sobre a filosofia de Agostinho. São Paulo: Discurso.

O’DALY, G. J. P. 19896. Aeternitas. In: Augustinus Lexikon, 1. Basel: Schwabe \& Co.

QUINN, J. M. 2019. Eternidade. In: FITZGERALD, A .D. (Org.). 2019. Agostinho através dos tempos: uma enciclopédia. São Paulo: Paulus. pp. 411-414. (col. "Filosofia Medieval”).

2019. Tempo. In: FITZGERALD, A .D. (Org.). 2019. Agostinho através dos tempos: uma enciclopédia. São Paulo: Paulus. pp. 909-916. (col. “Filosofia Medieval”).

RAVASI, G. 1992. 'Cantate a Dio con arte' - il teologico e il musicale nella Bibbia. In: TROIA, P. La Musica e la Bibbia - Atti del Convegno Internazionalle di Studi promosso da Biblia e dall'Accademia Musicale Chigiana. Siena 24-26 agosto 1990. Roma: Garamond.

SOTE, R. F. 2017. O livro VIII das Confissões de Agostinho de Hipona a partir das noções de caritas e cupiditas. São Paulo. 163p. Dissertação (Mestrado). Faculdade de Filosofia, Letras e Ciências Humanas, Universidade de São Paulo.

TESKE, R. 1996. Paradoxes of time in Saint Augustine. Milwaukee: Marquette University Press ("Aquinas Lecture", 60).

2008. To Know God and the Soul - Essays on the Thought of Saint Augustine. Washington, D.C.: The Catholic University of America Press.

Recebido em 27 de fevereiro de 2020. Aceito em 09 de março de 2021. 